\title{
Contribution of neuropsychiatric symptoms in Parkinson's disease to different domains of caregiver burden
}

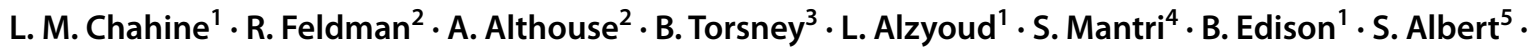

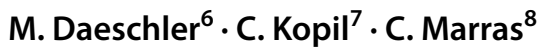

Received: 14 November 2020 / Revised: 31 January 2021 / Accepted: 3 February 2021 / Published online: 25 February 2021

(c) The Author(s) 2021

\begin{abstract}
Introduction Caregiver burden is high among caregivers of PD patients (CPD). Neuropsychiatric symptoms are leading contributors to CPD burden, but whether different symptoms differentially impact domains of caregiver burden is not known. Our objective was to examine which neuropsychiatric symptoms and demographic factors contribute to different domains of caregiver burden in PD.

Methods This was a cross-sectional online survey study. Participants were recruited from the Fox Insight (FI) study and were eligible if they identified themselves as a CPD. The primary outcome was the Caregiver Burden Inventory (CBI) total score and its 5 sub-domain scores. The Neuropsychiatric Inventory Questionnaire (NPI-Q) assessed caregiver-reported neuropsychiatric symptoms in the care recipient. Multivariable linear regression models were used to characterize the associations between NPI-Q symptom severity scores and CBI scores. Covariates were caregiver age, sex, education, and caregiving duration.

Results The sample consisted of 450 CPD, mean age 65.87 (SD 10.39) years, 74\% females. After adjusting for covariates, CBI total score was predicted by NPI-Q total score $(\beta=1.96, p<0.001)$; model adjusted $R^{2}=39.2 \%$. Anxiety severity had the largest effect size [standardized $\beta(\mathrm{s} \beta)=0.224$ ] on the time-dependency domain, which was also associated with female sex ( $\mathrm{s} \beta=-0.133$ ) and age ( $\mathrm{s} \beta=0.088$ ). Severity of disinhibition ( $\mathrm{s} \beta=0.218)$, agitation $(\mathrm{s} \beta=0.199)$, and female sex ( $\mathrm{s} \beta=0.104)$ were associated with greater emotional burden.

Conclusion Our findings indicate that demographic characteristics and specific neuropsychiatric symptoms contribute differentially to domains of caregiver burden. Tailored interventions to support CPD are needed.
\end{abstract}

Keywords Caregiver burden $\cdot$ Parkinson's disease $\cdot$ Neuropsychiatric symptoms $\cdot$ Caregiving

L. M. Chahine

lchahine2018@gmail.com

1 Department of Neurology, University of Pittsburgh School of Medicine, University of Pittsburgh, 3471 Fifth Avenue, Kaufmann Medical Building, Suite 811, Pittsburgh, PA 15213, USA

2 Center for Clinical Trials and Data Coordination, Division of General Internal Medicine, University of Pittsburgh School of Medicine, Pittsburgh, PA, USA

3 Temple University College of Education and Human Development, Philadelphia, PA, USA
4 Department of Neurology, Duke University School of Medicine, Durham, NC, USA

5 Behavioral and Community Health Sciences, Graduate School of Public Health, University of Pittsburgh, Pittsburgh, PA, USA

6 Columbia University, Columbia School of Social Work, New York, NY, USA

7 The Michael J. Fox Foundation for Parkinson's Research, New York, NY, USA

8 University of Toronto, University Health Center, Toronto, Canada 


\section{Introduction}

Parkinson's disease (PD) is the second most common neurodegenerative disorder, and its prevalence is increasing worldwide $[1,2]$. PD is marked by inexorable progression of motor and nonmotor symptoms over the course of the disease. As the disease progresses, individuals require increasing assistance with activities of daily living [3]. Informal caregivers provide the majority of care and support for individuals with PD in the United States [4]. Caregiver burden - the negative consequences of caregiving on the caregiver-is high among caregivers of PD patients (CPD), and can adversely affect the physical and mental health of both the caregiver and the PD patient [5]. Therefore, understanding the contributors to caregiver burden in PD is critical.

PD manifestations in the care recipient (the PD patient whom the caregiver is providing care for) are a key determinant of caregiver burden in PD. While motor severity and motor complications in PD have some contribution to caregiver burden, non-motor symptoms have a greater impact. Indeed, multiple studies from diverse populations have shown that neuropsychiatric symptoms, including psychosis, apathy, depression, and dementia, are the leading contributors to caregiver burden in PD [6-11]. These neuropsychiatric symptoms in the care recipient could be assessed via physician, patient, and/or caregiver report. Given that caregiver perception of disease manifestations and severity in the care recipient could have a strong influence on caregiver burden, examining the relationship between caregiverreported neuropsychiatric manifestations of PD in the care recipient and measures of caregiver burden is crucial [12-14].

Caregiver burden is multidimensional, encompassing physical, emotional, and financial aspects [15], among others. Most studies of caregiver burden in PD have used global measures, and the contributors to different domains of caregiver burden in PD are not known. Given the established strong contribution of neuropsychiatric symptoms to caregiver burden of CPD [6-9], understanding whether different neuropsychiatric symptoms also differentially impact domains of caregiver burden is important towards providing meaningful, personalized support to CPD. Towards the latter, determining whether caregiver characteristics also have differential impacts on each domain is important and, to our knowledge, has been minimally studied in PD. We aimed to examine, among a large cohort of CPD, which caregiver demographics and caregiver-reported neuropsychiatric symptoms in the care recipient contribute to different domains of caregiver burden in PD.

\section{Methods}

\section{Sample}

This was a cross-sectional study that was carried out as part of a research program investigating caregiver burden in PD
$[16,17]$. Participants were recruited from the Fox insight (FI) study, an online-only study in which individuals with and without self-reported PD participate in online assessments [18]. FI participants were considered eligible to participate in this study if they had identified themselves as being caregivers of patients with PD. An email invitation was sent to eligible individuals, and those clicking on a link in the email went on to receive the survey. Individuals could also participate if they: (1) were forwarded the email invitation, (2) enrolled in FI after the email invitation was sent, they could view the survey and opt to click on it for potential participation. Only individuals completing all items on the neuropsychiatric symptoms and caregiver burden questionnaires were included in this analysis (see below; Fig. 1).

\section{Assessments}

- Demographics - caregiver age, sex, education

- PD disease duration in care recipient

- Caregiver role - a series of questions determined if the respondent was the primary caregiver, was employed outside the home, was paid, and if they lived with the patient.

To evaluate caregiver responsibilities, participants were asked to select all tasks that applied from the following: assisting with personal care (e.g., helping with bathing, grooming, dressing, etc.), food preparation, obtaining and/ or administering prescribed medications, general health care (such as scheduling medical appointments, making sure they get to appointments, etc., but does not include medications), mobility assistance (e.g., helping them getting up from a chair, assisting with balance), providing emotional support, transportation, home organization (e.g., cleaning and

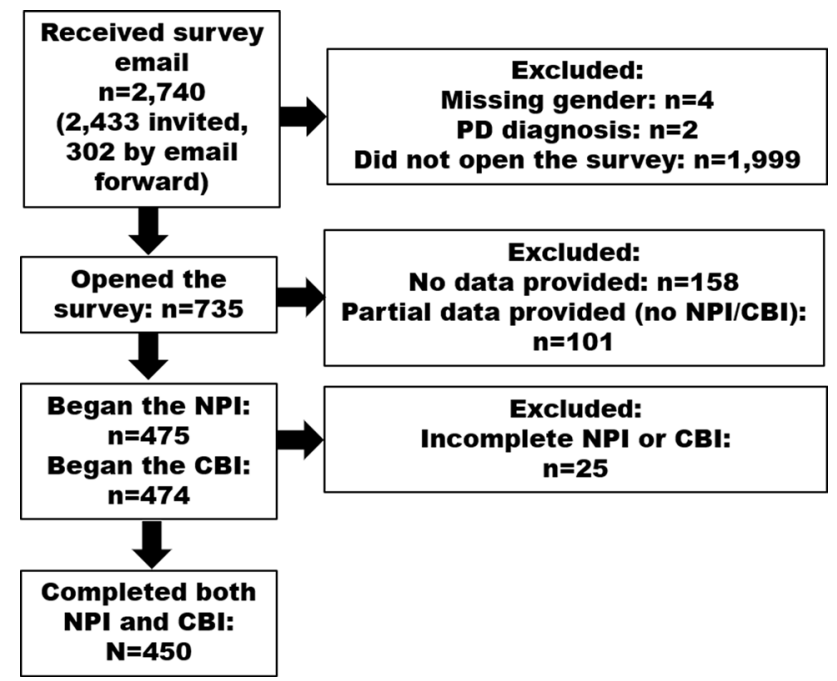

Fig. 1 Flow diagram of potentially eligible and final studied sample 
organizing the home), handling a crisis or medical emergency, financial responsibilities, or other.

- Neuropsychiatric Inventory Questionnaire (NPI-Q) [19] was completed by the CPD and used to ascertain neuropsychiatric symptoms in the care recipient. The NPI-Q is a 12-item respondent-administered questionnaire derived from the interview-based NPI [20] which assesses the presence/absence and severity (mild, moderate, severe) of behavioral and neurovegetative symptoms in the care recipient over the prior 4 weeks, and the resulting distress in the caregiver. The NPI-Q total score is the sum of individual symptom severity scores, ranging from 0 to 36 . The caregiver distress score does not contribute to the overall total score.

- Caregiver Burden Inventory (CBI) [15] was used to assess caregiver burden. The CBI is a 24-item respondent-administered questionnaire with responses ranging from 0 (never) to 4 (almost always), and maximum total score of 84. It measures burden in 5 domains. The timedependence domain encompasses burden due to the caregiver's time being consumed by caring for the patient. Developmental burden relates to where the caregiver sees themselves in relation to their peers and where they envisioned they would be in their life in relation to their peers and their own life goals. Physical burden encompasses caregiver fatigue and health. The social burden domain of the CBI relates to the relationship of the caregiver to the care recipient and their family. Finally, emotional burden domain encompasses the feelings of the caregiver toward the care recipient, including embarrassment, shame, resentment, anger, or discomfort. All subdomains have 5 questions contributing to them except the physical domain which has 4.

\section{Statistical analysis}

Sample characteristics, NPI-Q score, and CBI score and subscores were summarized with basic descriptive statistics [mean (SD) for continuous variables; frequencies and percentages for categorical variables].

Multivariable linear regression models were used to characterize the associations between NPI-Q total score (independent variables) and CBI total score or each of the $5 \mathrm{CBI}$ domain subscores while adjusting for potential confounders. Covariates were selected based on their relationship with caregiver burden from the literature, namely caregiver age, sex, education, and caregiving duration $[4,6,8,21]$. The same procedure was followed to model associations between NPI-Q individual symptom severity scores and the CBI total score as well as each of the 5 domain subscores. Scatterplots of the expected (fitted) values for CBI versus the actual (observed) values are included to illustrate how accurately caregiver burden may be predicted based on NPI symptoms.

All statistical analyses were performed using $\mathrm{R}$ version 3.6.3.

\section{Results}

2740 individuals received the study invitation by email, and 741 clicked on the link to open the survey (Fig. 1). Compared to those who did not open the survey, those who did were older ( 64.9 vs 62.5 years, $p<0.001)$ and more likely to be male (29.4 male vs $20.6 \%$ male, $p<0.001$, respectively). Among those who did not access the survey, data on age and sex were missing on 3 and 136, respectively.

The final sample was 450 individuals. Cohort characteristics are shown in Table 1. Mean age of the CPD was 65.87 (SD 10.39) years, and the majority were female (74\%). Caregivers in this sample were predominantly spouses (84.9\%), and $90.7 \%$ indicated they were the primary caregivers for the care recipient. Average duration of caregiving was 5.47 (SD 5.66) years. Half of the sample were full-time caregivers and $27 \%$ provided at least some daily care. Mean CBI total score was 31.73 (SD 17.66).

An average of 3.63 (SD 2.63) symptoms in the care recipient were reported on the NPI-Q. NPI-Q total score was mean (SD) 6.33 (5.51). The most common neuropsychiatric symptoms reported were nighttime behaviors, depression, apathy, and irritability (Table 2). In general, severe symptoms in the care recipient (as rated by the CPD) were associated with moderate to severe distress in the care partner, but some also reported severe distress from mild symptoms or mild distress even with severe symptoms (Fig. 2).

The following regression results are presented as the change in expected value of CBI total or subscore per onepoint increase in NPI-Q total score. In a linear regression model with CBI total score as the outcome and NPI total score as predictor, with caregiver age, sex, education, and duration of caregiving as covariates, the only variable associated with CBI total score was NPI total score $(\beta=1.957$, $p=<0.001,95 \%$ CI 1.717-2.197); adjusted $R^{2}=39.2 \%$.

For the contribution of severity of individual neuropsychiatric symptoms, Table 3 shows significant contributors in the linear regression models predicting CBI total score and each subscore; supplementary table 1 shows the full model.

Significant contributors to the CBI total score, in order of greatest contribution [based on the magnitude of the standardized $\beta$-coefficient $(\mathrm{s} \beta)]$ were severity of agitation ( $\mathrm{s} \beta=0.180)$, anxiety $(\mathrm{s} \beta=0.170)$, apathy $(\mathrm{s} \beta=0.168)$, nighttime behaviors $(\mathrm{s} \beta=0.118)$, hallucinations 
Table 1 Cohort characteristics

\begin{tabular}{|c|c|}
\hline Variable & Result \\
\hline $\begin{array}{l}\text { Age of caregiver, } \\
\text { mean years (SD; } \\
\text { range) }\end{array}$ & $65.87(10.39 ; 22.4-90.8)$ \\
\hline Sex M:F $N(\%)$ & 117 (26): $333(74)$ \\
\hline \multicolumn{2}{|c|}{ Education of caregiver $N(\%)$} \\
\hline $\begin{array}{l}\text { Less than } \\
9 \text { years }\end{array}$ & $5(1.1)$ \\
\hline $9-12$ years & $32(7.1)$ \\
\hline $13-16$ years & $240(53.3)$ \\
\hline $\begin{array}{l}\text { More than } \\
16 \text { years }\end{array}$ & $173(38.4)$ \\
\hline \multicolumn{2}{|c|}{ Relation of caregiver $N(\%)$} \\
\hline Spouse/partner & $382(84.9)$ \\
\hline Parent & $46(10.2)$ \\
\hline Sibling & $8(1.8)$ \\
\hline Uncle/aunt & $0(0)$ \\
\hline Employer & $0(0)$ \\
\hline Other & $14(3.1)$ \\
\hline $\begin{array}{l}\text { Duration of caregiv- } \\
\text { ing, mean years } \\
\text { (SD) }\end{array}$ & $5.47(5.66)$ \\
\hline $\begin{array}{l}\text { Disease duration } \\
\text { of care recipient, } \\
\text { mean years }(\mathrm{SD})\end{array}$ & $8.33(6.43)$ \\
\hline $\begin{array}{l}\text { Principal caregiver } \\
N(\%)\end{array}$ & $408(90.7)$ \\
\hline $\begin{array}{l}\text { Employed outside } \\
\text { the home } N(\%)\end{array}$ & $140(31.1)$ \\
\hline \multicolumn{2}{|l|}{ Role of caregiver $N(\%)$} \\
\hline $\begin{array}{l}\text { Not paid-lives } \\
\text { with patient }\end{array}$ & $396(88)$ \\
\hline $\begin{array}{l}\text { Not paid- } \\
\text { doesn't live with } \\
\text { patient }\end{array}$ & $48(10.7)$ \\
\hline $\begin{array}{l}\text { Paid and lives } \\
\text { with patient }\end{array}$ & $4(0.9)$ \\
\hline $\begin{array}{l}\text { Paid and doesn't } \\
\text { live with patient }\end{array}$ & $2(0.4)$ \\
\hline \multicolumn{2}{|c|}{ Time spent caregiving per week $N(\%)(N=450)$} \\
\hline Full time & $217(48.2)$ \\
\hline $\begin{array}{l}\text { A few hours a } \\
\text { day every day }\end{array}$ & $123(27.3)$ \\
\hline $\begin{array}{l}\text { A few days a } \\
\text { week but not } \\
\text { every day }\end{array}$ & $44(9.8)$ \\
\hline $\begin{array}{l}\text { One day during } \\
\text { the week or less }\end{array}$ & $63(14)$ \\
\hline Not answered & $3(0.7)$ \\
\hline $\begin{array}{l}\text { Caregiver Burden } \\
\text { Index, mean (SD) }\end{array}$ & $31.73(17.66)$ \\
\hline \multicolumn{2}{|c|}{ Caregiver Burden Subscore, mean (SD) } \\
\hline Time & $9.71(5.42)$ \\
\hline Development & $8.69(5.35)$ \\
\hline Physical & $6.12(3.66)$ \\
\hline
\end{tabular}

Table 1 (continued)

\begin{tabular}{|c|c|}
\hline Variable & Result \\
\hline Emotional & $3.49(3.59)$ \\
\hline Social & $3.72(3.89)$ \\
\hline \multicolumn{2}{|c|}{ Caregiving responsibilities $N(\%)$} \\
\hline $\begin{array}{l}\text { Assisting with } \\
\text { personal care }\end{array}$ & $202(44.9)$ \\
\hline $\begin{array}{l}\text { Food prepara- } \\
\text { tion }\end{array}$ & $304(67.6)$ \\
\hline $\begin{array}{l}\text { Obtaining and/ } \\
\text { or administer- } \\
\text { ing prescribed } \\
\text { medications }\end{array}$ & $245(54.4)$ \\
\hline $\begin{array}{l}\text { General health } \\
\text { care besides } \\
\text { medications }\end{array}$ & $302(67.1)$ \\
\hline $\begin{array}{l}\text { Mobility assis- } \\
\text { tance }\end{array}$ & $202(44.9)$ \\
\hline $\begin{array}{l}\text { Providing emo- } \\
\text { tional support }\end{array}$ & $416(92.4)$ \\
\hline Transportation & $310(68.9)$ \\
\hline $\begin{array}{l}\text { Home organi- } \\
\text { zation (e.g., } \\
\text { cleaning and } \\
\text { organizing the } \\
\text { home) }\end{array}$ & $333(74.0)$ \\
\hline $\begin{array}{l}\text { Handling a } \\
\text { crisis or medical } \\
\text { emergency }\end{array}$ & $309(68.7)$ \\
\hline $\begin{array}{l}\text { Financial } \\
\text { responsibilities }\end{array}$ & $281(62.4)$ \\
\hline $\begin{array}{l}\text { Other (indoor/ } \\
\text { outdoor home } \\
\text { repairs, caring } \\
\text { for children and } \\
\text { other family } \\
\text { members) }\end{array}$ & $89(19.8)$ \\
\hline
\end{tabular}

( $\mathrm{s} \beta=0.109$ ), and depression ( $\mathrm{s} \beta=0.086)$. Adjusted $R^{2}$ for the model $39.9 \%$.

Significant contributors to the time-dependency domain, in order of greatest contribution, were severity of anxiety $(\mathrm{s} \beta=0.224)$, hallucinations $(\mathrm{s} \beta=0.172)$, female sex ( $\mathrm{s} \beta=-0.133)$, severity of apathy $(\mathrm{s} \beta=0.124)$, duration of caregiving ( $\mathrm{s} \beta=0.114)$, nighttime behaviors ( $\mathrm{s} \beta=0.098$ ), and age ( $\mathrm{s} \beta=0.088$ ). Adjusted $R^{2}$ for the model was $38.5 \%$.

Significant contributors to the developmental domain, in order of greatest contribution, were severity of apathy ( $\mathrm{s} \beta=0.217)$, anxiety $(\mathrm{s} \beta=0.169)$, nighttime behaviors ( $\mathrm{s} \beta=0.145)$, agitation $(\mathrm{s} \beta=0.123)$, and hallucinations ( $\mathrm{s} \beta=0.101$ ). Adjusted $R^{2}$ for the model was $35.7 \%$.

Significant contributors to the physical domain, in order of greatest contribution, were severity of nighttime behaviors ( $\mathrm{s} \beta=0.147)$, anxiety ( $\mathrm{s} \beta=0.133)$, depression ( $\mathrm{s} \beta=0.131$ ), 
apathy ( $\mathrm{s} \beta=0.112)$, and agitation $(\mathrm{s} \beta=0.096)$. Adjusted $R^{2}$ for the model was $27.5 \%$.

Significant contributors to the emotional domain, in order of greatest contribution were severity of disinhibition $(\mathrm{s} \beta=0.218)$, agitation $(\mathrm{s} \beta=0.199)$, and female sex (s $\beta=0.104$ ). Adjusted $R^{2}$ for the model was $21.0 \%$.

Significant contributors to the social domain, in order of greatest contribution were severity of agitation ( $\mathrm{s} \beta=0.253)$, age ( $\mathrm{s} \beta=-0.193)$, and apathy ( $\mathrm{s} \beta=0.103)$. Adjusted $R^{2}$ for the model was $21.2 \%$.

Figure 3 plots the expected value of CBI scores (based on the regression models from Table 3) against the actual (observed) values, providing a graphical representation of how much of the variation in CBI scores is explained by NPI-Q symptom severity. The positive associations for each plot (with correlation coefficients ranging from 0.49 to 0.65 ) suggest that NPI-Q symptoms explain a substantial amount of variation in the CBI scores, indicating that patient symptom severity is a strong contributor to caregiver burden.

\section{Discussion}

Our findings highlight the complex, multidimensional, and multifactorial nature of caregiver burden in PD. Neuropsychiatric symptoms explained a substantial proportion of the variance in global caregiver burden, with anxiety, agitation, and apathy having the largest effect sizes. Importantly, specific neuropsychiatric symptoms and caregiver demographics contributed differentially to each domain of caregiver burden.

The time-dependence domain of caregiving relates to the extent to which the caregiver's time is consumed by caring for the patient [15]. Each of the neuropsychiatric contributors to the time-dependence domain, namely hallucinations [22], anxiety [23], apathy [24], and nighttime behaviors [25] have been associated with greater disability and functional impairment in activities of daily living in PD. Thus, the caregiver of a patient with these neuropsychiatric symptoms may spend large amounts of time assisting and/or monitoring the patient, in turn allowing the caregiver less time for themselves. Indeed, the majority of caregivers in our sample reported providing care either full time or at least several hours every day. The most commonly reported responsibility, for $92 \%$ of caregivers, was the provision of emotional support to the patient. Consistent with this, anxiety severity in the care recipient had the largest effect size for the time-dependency domain of the CBI in the multivariable model. These findings raise at least three opportunities for intervention to improve time-dependency burden of caregiving for CPD: (1) identifying and treating anxiety and other neuropsychiatric symptoms in the care recipient, (2) providing education and tools to caregivers on how to address anxiety in the care recipient, and (3) providing respite care as a "break" from caregiving so that CPD may have time to themselves. Respite care may improve caregiver resilience and reduce caregiver burden [26]. Studies are needed to better understand the most useful means of delivering respite care for CPD, and in different settings.

Physical burden was influenced by apathy, anxiety, and nighttime behaviors, in addition to agitation. Greater functional dependence of the care recipient on the caregiver could be contributing to greater demands not only on the caregiver's time but also on physical health. As with the time-dependency domain, anxiety had the largest effect size for the physical domain as well. Increased anxiety in the care recipient may prompt increased reliance on the caregiver, and in turn may even reduce the ability of the caregiver to maintain a support network [11]. This could reduce the direct or indirect respite care available to the caregiver [11], exacerbating physical burden. Behavioral and occupational therapy interventions to reduce time requirements as well as physical demands and exertion for caregiving in PD require study. A few randomized trials explored such interventions in PD [11], and did not demonstrate clear benefit. However, the primary outcomes for these trials were global measures of caregiver burden [27, 28], and did not specifically examine the physical burden domain.

The construct of developmental burden encompasses the caregiver's feelings regarding where they are in life compared to where they thought they would be or want to be [15]. Developmental burden has been associated with greater depression and lower caregiver satisfaction [29]. In our sample of CPD, it was influenced by hallucinations, anxiety, apathy, and nighttime behaviors, as well as agitation. Nighttime behaviors had the largest effect size. This is consistent with studies demonstrating a strong contribution of nocturnal symptoms in the care recipient to caregiver burden in PD [11, 30, 31]. This highlights not only the importance of treating nighttime symptoms in $\mathrm{PD}$, but also the importance of incorporating caregiver burden outcome measures in any treatment intervention for nighttime symptoms in PD. Because developmental burden may be largely influenced by thought patterns and perceptions of the caregiver, counseling interventions designed to provide coping strategies to address this aspect of caregiver burden may also be useful [32]. This is also the case for emotional burden, which in the CBI relates to the caregiver's feelings toward the care recipient.

Agitation and disinhibition were the main determinants of emotional burden, along with caregiver sex. This is consistent with data from other small studies of caregivers of dementia patients which indicated that feelings of resentment toward the care recipient were present among caregivers of patients with agitation and disinhibition [33, 34]. Importantly, a perception of willfulness [i.e., that the care 
Table 2 Prevalence of neuropsychiatric symptoms in care recipient by levels of symptom severity and caregiver distress

\begin{tabular}{|c|c|c|c|c|c|c|c|}
\hline \multirow[t]{2}{*}{ Measure } & \multirow{2}{*}{$\begin{array}{l}N(\% \text { of those } \\
\text { with symptoms })\end{array}$} & \multicolumn{6}{|c|}{ Distress $N$ (\% of those with specified symptom severity) } \\
\hline & & Not distressing & Minimal & Mild & Moderate & Severe & Extreme \\
\hline \multicolumn{8}{|c|}{ Delusions $(N=58)$} \\
\hline Mild & $21(36.2)$ & $1(4.8)$ & $4(19)$ & $9(42.9)$ & $7(33.3)$ & $0(0)$ & $0(0)$ \\
\hline $\begin{array}{l}\text { Moder- } \\
\text { ate }\end{array}$ & $29(50)$ & $0(0)$ & $2(6.9)$ & $6(20.7)$ & $15(51.7)$ & $6(20.7)$ & $0(0)$ \\
\hline Severe & $8(13.8)$ & $0(0)$ & $0(0)$ & $0(0)$ & $5(62.5)$ & $2(25)$ & $1(12.5)$ \\
\hline \multicolumn{8}{|c|}{ Hallucinations $(N=118)$} \\
\hline Mild & $64(54.2)$ & $9(14.1)$ & $24(37.5)$ & $22(34.4)$ & $7(10.9)$ & $2(3.1)$ & $0(0)$ \\
\hline $\begin{array}{l}\text { Moder- } \\
\text { ate }\end{array}$ & $43(36.4)$ & $0(0)$ & $8(18.6)$ & $11(25.6)$ & $21(48.8)$ & $3(7)$ & $0(0)$ \\
\hline Severe & $11(9.3)$ & $0(0)$ & $0(0)$ & $0(0)$ & $7(63.6)$ & $4(36.4)$ & $0(0)$ \\
\hline \multicolumn{8}{|c|}{ Agitation $(N=135)$} \\
\hline Mild & $71(52.6)$ & $2(2.8)$ & $17(23.9)$ & $25(35.2)$ & $23(32.4)$ & $4(5.6)$ & $0(0)$ \\
\hline $\begin{array}{l}\text { Moder- } \\
\text { ate }\end{array}$ & 49 (36.3) & $0(0)$ & $3(6.1)$ & $8(16.3)$ & $33(67.3)$ & $5(10.2)$ & $0(0)$ \\
\hline Severe & $15(11.1)$ & $0(0)$ & $0(0)$ & $0(0)$ & $5(33.3)$ & $8(53.3)$ & $2(13.3)$ \\
\hline \multicolumn{8}{|c|}{ Depression $(N=215)$} \\
\hline Mild & $92(42.8)$ & $0(0)$ & $23(25)$ & $44(47.8)$ & $22(23.9)$ & $3(3.3)$ & $0(0)$ \\
\hline $\begin{array}{l}\text { Moder- } \\
\text { ate }\end{array}$ & $98(45.6)$ & $0(0)$ & $5(5.1)$ & $24(24.5)$ & $62(63.3)$ & $7(7.1)$ & $0(0)$ \\
\hline Severe & 25 (11.6) & $0(0)$ & $0(0)$ & $1(4)$ & $13(52)$ & $10(40)$ & $1(4)$ \\
\hline \multicolumn{8}{|c|}{ Anxiety $(N=140)$} \\
\hline Mild & $57(40.7)$ & $3(5.3)$ & $22(38.6)$ & $17(29.8)$ & $12(21.1)$ & $3(5.3)$ & $0(0)$ \\
\hline $\begin{array}{l}\text { Moder- } \\
\text { ate }\end{array}$ & $69(49.3)$ & $3(4.3)$ & $3(4.3)$ & $14(20.3)$ & $41(59.4)$ & 8 (11.6) & $0(0)$ \\
\hline Severe & $14(10)$ & $0(0)$ & $0(0)$ & $1(7.1)$ & $8(57.1)$ & $5(35.7)$ & $0(0)$ \\
\hline \multicolumn{8}{|c|}{ Euphoria $(N=23)$} \\
\hline Mild & $6(26.1)$ & $4(66.7)$ & $0(0)$ & $1(16.7)$ & $1(16.7)$ & $0(0)$ & $0(0)$ \\
\hline $\begin{array}{l}\text { Moder- } \\
\text { ate }\end{array}$ & $16(69.6)$ & $2(12.5)$ & $3(18.8)$ & $7(43.8)$ & $3(18.8)$ & $1(6.2)$ & $0(0)$ \\
\hline Severe & $1(4.3)$ & $0(0)$ & $0(0)$ & $0(0)$ & $1(100)$ & $0(0)$ & $0(0)$ \\
\hline \multicolumn{8}{|c|}{ Apathy $(N=195)$} \\
\hline Mild & $62(31.8)$ & $4(6.5)$ & $28(45.2)$ & $21(33.9)$ & $7(11.3)$ & $2(3.2)$ & $0(0)$ \\
\hline $\begin{array}{l}\text { Moder- } \\
\text { ate }\end{array}$ & 97 (49.7) & $0(0)$ & $7(7.2)$ & $35(36.1)$ & $51(52.6)$ & $4(4.1)$ & $0(0)$ \\
\hline Severe & $36(18.5)$ & $0(0)$ & $1(2.8)$ & $1(2.8)$ & $22(61.1)$ & $11(30.6)$ & $1(2.8)$ \\
\hline \multicolumn{8}{|c|}{ Disinhibition $(N=75)$} \\
\hline Mild & $37(49.3)$ & $3(8.1)$ & $16(43.2)$ & $12(32.4)$ & $6(16.2)$ & $0(0)$ & $0(0)$ \\
\hline $\begin{array}{l}\text { Moder- } \\
\text { ate }\end{array}$ & $31(41.3)$ & $0(0)$ & $1(3.2)$ & 7 (22.6) & $20(64.5)$ & $3(9.7)$ & $0(0)$ \\
\hline Severe & $7(9.3)$ & $0(0)$ & $1(14.3)$ & $0(0)$ & $1(14.3)$ & $4(57.1)$ & $1(14.3)$ \\
\hline \multicolumn{8}{|c|}{ Irritability $(N=174)$} \\
\hline Mild & $71(40.8)$ & $1(1.4)$ & $31(43.7)$ & $20(28.2)$ & $19(26.8)$ & $0(0)$ & $0(0)$ \\
\hline $\begin{array}{l}\text { Moder- } \\
\text { ate }\end{array}$ & $91(52.3)$ & $1(1.1)$ & $4(4.4)$ & $24(26.4)$ & $58(63.7)$ & $4(4.4)$ & $0(0)$ \\
\hline Severe & $12(6.9)$ & $0(0)$ & $0(0)$ & $1(8.3)$ & $4(33.3)$ & $5(41.7)$ & $2(16.7)$ \\
\hline \multicolumn{8}{|c|}{ Motor disturbance $(N=72)$} \\
\hline Mild & $28(38.9)$ & $8(28.6)$ & $10(35.7)$ & $10(35.7)$ & $0(0)$ & $0(0)$ & $0(0)$ \\
\hline $\begin{array}{l}\text { Moder- } \\
\text { ate }\end{array}$ & $33(45.8)$ & $3(9.1)$ & $1(3)$ & $12(36.4)$ & $16(48.5)$ & $1(3)$ & $0(0)$ \\
\hline Severe & $11(15.3)$ & $0(0)$ & $2(18.2)$ & $1(9.1)$ & $3(27.3)$ & $5(45.5)$ & $0(0)$ \\
\hline
\end{tabular}


Table 2 (continued)

\begin{tabular}{|c|c|c|c|c|c|c|c|}
\hline \multirow[t]{2}{*}{ Measure } & \multirow{2}{*}{$\begin{array}{l}N(\% \text { of those } \\
\text { with symptoms) }\end{array}$} & \multicolumn{6}{|c|}{ Distress $N$ (\% of those with specified symptom severity) } \\
\hline & & Not distressing & Minimal & Mild & Moderate & Severe & Extreme \\
\hline \multicolumn{8}{|c|}{ Nighttime behaviors $(N=277)$} \\
\hline Mild & $74(26.7)$ & $5(6.8)$ & $33(44.6)$ & $23(31.1)$ & $13(17.6)$ & $0(0)$ & $0(0)$ \\
\hline $\begin{array}{l}\text { Moder- } \\
\text { ate }\end{array}$ & $155(56)$ & $1(0.6)$ & $34(21.9)$ & $47(30.3)$ & $68(43.9)$ & $5(3.2)$ & $0(0)$ \\
\hline Severe & $48(17.3)$ & $1(2.1)$ & $1(2.1)$ & $4(8.3)$ & $21(43.8)$ & $18(37.5)$ & $3(6.2)$ \\
\hline \multicolumn{8}{|c|}{ Appetite/eating $(N=151)$} \\
\hline Mild & $53(35.1)$ & $11(20.8)$ & $21(39.6)$ & $17(32.1)$ & $2(3.8)$ & $1(1.9)$ & 1 (1.9) \\
\hline $\begin{array}{l}\text { Moder- } \\
\text { ate }\end{array}$ & $67(44.4)$ & $2(3)$ & $14(20.9)$ & $23(34.3)$ & $26(38.8)$ & $2(3)$ & $0(0)$ \\
\hline Severe & $31(20.5)$ & $0(0)$ & $0(0)$ & $4(12.9)$ & $16(51.6)$ & $9(29)$ & $2(6.5)$ \\
\hline
\end{tabular}

recipient is behaving in an agitated and disinhibited manner willfully ("on purpose")] is associated with caregiver resentment. The detection of emotional burden offers an opportunity to provide targeted education to caregivers toward the often-involuntary nature of agitation and disinhibition that occurs in, for example, PD dementia. Similarly, counseling interventions may be designed specifically to address the contribution of apathy and agitation to social burden. Apathy may influence social relationships, including between the caregiver and care recipient [35]. Preemptive caregiver education and support could reduce caregiver social isolation and loneliness [36, 37]. Several educational tools are available for PD patients and their caregivers, including materials developed via systematic approaches [38]. Controlled studies are needed, however, to determine the efficacy of these educational tools in alleviating caregiver burden and its specific domains.

Our findings indicate that there are demographic differences in different domains of caregiver burden in PD. Older age was associated with greater burden in the timedependency domain, whereas younger age was associated with greater burden in the social domain. On the other hand, male sex was associated with greater time domain burden whereas female sex was associated with greater emotional domain burden. Little is known about sex differences in different caregiver burden domains in PD. Among older informal partner caregivers in the Netherlands, a similar pattern was noted [39], females were less likely than males to be burdened in the time domain, but had greater social burden. Factors behind these sex differences require further study. These results highlight the importance of tailored support programs for caregivers based on their age, sex, and relationship to the care recipient.

The symptoms assessed by the NPI-Q are strongly associated with cognitive dysfunction and dementia, though they can occur independently. The impact of psychosis symptoms on caregiver burden in PD may be greater when the care recipient has dementia [8]. Our study design did not allow us to determine cognitive function in the care recipient, and the mediation of the relationship between the neuropsychiatric symptoms, cognition, and CPD characteristics to each domain of caregiver burden requires study. Our study design also did not allow for an examination of motor severity and manifestations in the care recipient as a determinant of caregiver burden. While the severity of motor symptoms in the care recipient does influence caregiver burden, several studies have demonstrated a relatively minor contribution of motor disease severity to caregiver burden in PD compared to non-motor symptoms [8, 11, 30, 40]. In one study [41], the contribution of motor symptoms and 2 non-motor symptoms, depression and cognitive dysfunction, to spouse's depression and strain was examined. Motor symptoms only explained $0-6 \%$ of the variance of caregiver strain compared to $7-13 \%$ explained by cognitive dysfunction/depression symptoms [41].

Regarding the means of assessment of neuropsychiatric symptoms in this study, caregivers' report of neuropsychiatric symptoms in the care recipient has a strong established relationship with caregiver burden [6-11]. However, neuropsychiatric symptom burden in the care recipient as reported by the CPD is not always concordant with patient report or physician diagnosis [13, 14]. Indeed, caregivers may be more likely to report apathy and depression and less likely to report anxiety [14] and hallucinations [42]. However, it is notable that even when caregiver and physician/ patient assessment of given neuropsychiatric symptoms is not concordant, caregiver perception of these symptoms still strongly influences caregiver distress and, importantly, caregiver distress may influence reporting of some symptoms in the care recipient as well $[13,14]$. This has implications for design of caregiver support programs, emphasizing the importance of not only treating neuropsychiatric symptoms in the care recipient as appropriate, but also educating and otherwise supporting the caregiver in their own right. 


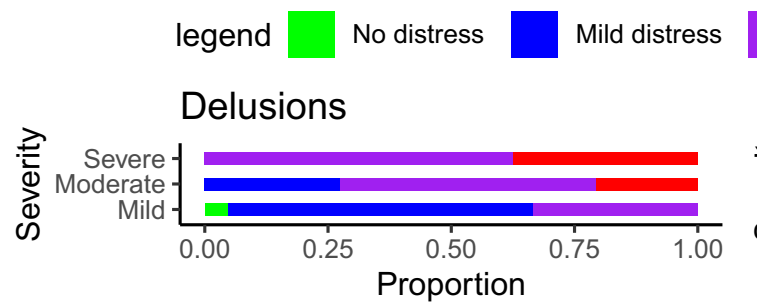

Moderate distress
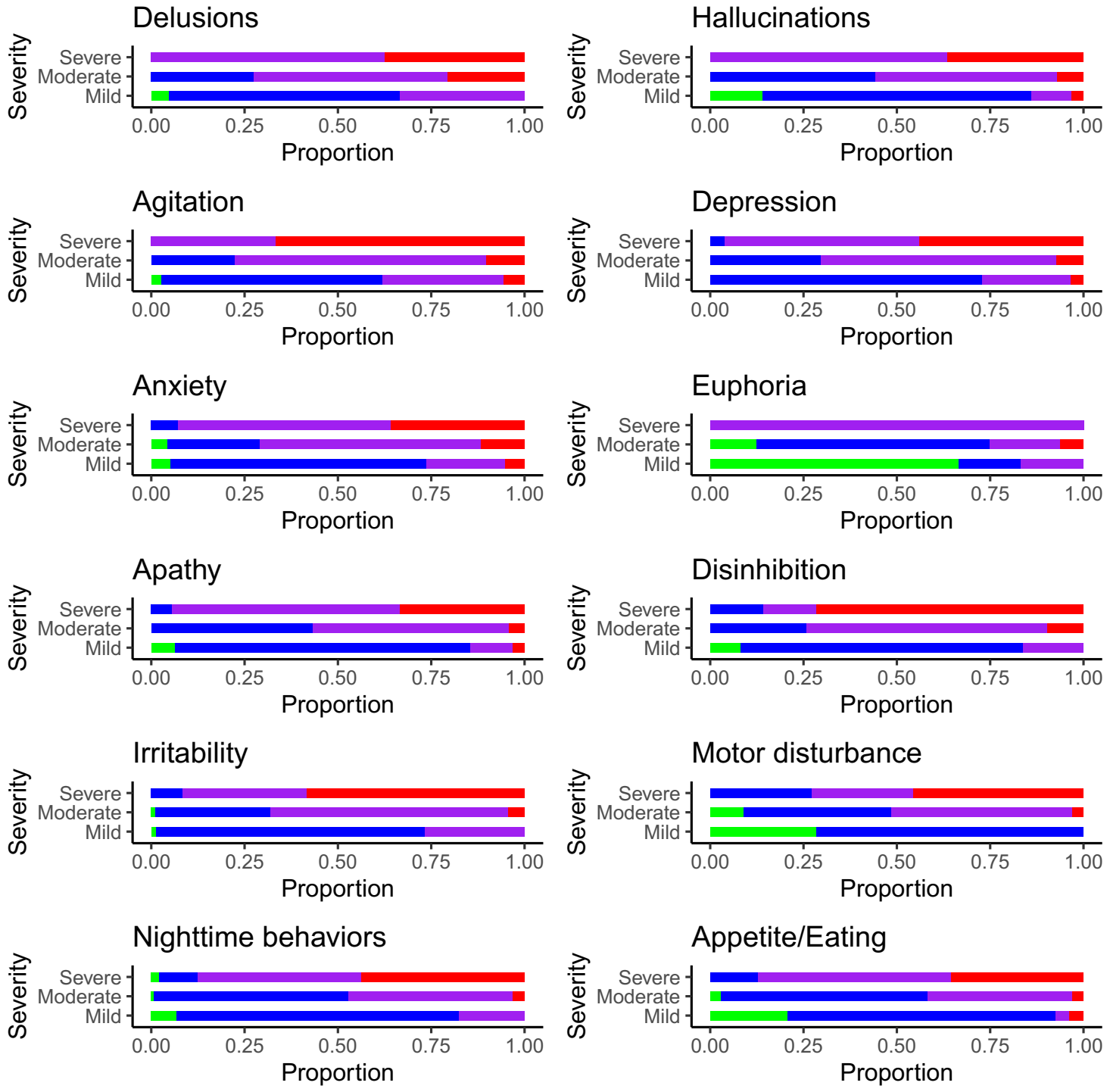

Fig. 2 For each symptom on the NPI-Q, the proportion of caregivers reporting a given level of distress for a given severity of the symptom (in the care recipient) is shown (the mild distress category combines

minimal and mild distress and the severe distress category combines severe and extreme distress)

The large sample size and the application of a multidomain caregiver burden questionnaire are noted strengths of this study. The strengths and limitations of using a caregiver-reported measure of neuropsychiatric symptoms in the care recipient have been discussed above. In addition, while the caregiver-reported NPI-Q shows strong concordance with the rigorously validated intervieweradministered NPI [43], online administration of the NPI-Q

does not allow for the recommended clinician review of responses. Extension of our work, using other measures of neuropsychiatric symptoms-whether reported by the CPD, the patient, or the healthcare provider-will be important. The FI study does not currently allow the linking of caregiver-reported data and data reported by the care recipient but future work may introduce this functionality into the study, thus allowing for an examination 
Table 3 Significant neuropsychiatric and demographic contributors to domains of caregiver burden

\begin{tabular}{|c|c|c|c|c|c|c|}
\hline Outcome & Predictors & $\begin{array}{l}\text { Standardized } \beta \\
\text { coefficient }\end{array}$ & $p$ value & $\beta$ coefficient & $95 \% \mathrm{CI}$ & Adjusted $R^{2}$ \\
\hline \multirow[t]{6}{*}{ CBI total score } & Agitation severity & 0.180 & $<0.001$ & 3.893 & $2.0,5.786$ & 0.399 \\
\hline & Anxiety severity & 0.170 & $<0.001$ & 3.472 & $1.793,5.151$ & \\
\hline & Apathy severity & 0.168 & $<0.001$ & 2.875 & $1.405,4.345$ & \\
\hline & Nighttime behaviors severity & 0.118 & 0.005 & 1.957 & $0.581,3.333$ & \\
\hline & Hallucinations severity & 0.109 & 0.025 & 2.531 & $0.318,4.744$ & \\
\hline & Depression severity & 0.086 & 0.049 & 1.568 & $0.007,3.129$ & \\
\hline \multirow[t]{7}{*}{ Time dependency } & Anxiety severity & 0.224 & $<0.001$ & 1.407 & $0.886,1.928$ & 0.385 \\
\hline & Hallucinations severity & 0.172 & $<0.001$ & 1.228 & $0.540,1.916$ & \\
\hline & Female sex & -0.133 & 0.001 & -1.642 & $-2.591,-0.693$ & \\
\hline & Apathy severity & 0.124 & 0.005 & 0.650 & $0.194,1.106$ & \\
\hline & Duration of caregiving & 0.114 & 0.004 & 0.110 & $0.035,0.185$ & \\
\hline & Nighttime behaviors severity & 0.098 & 0.022 & 0.500 & $0.073,0.927$ & \\
\hline & Age & 0.088 & 0.027 & 0.046 & $0.005,0.087$ & \\
\hline \multirow[t]{5}{*}{ Development } & Apathy severity & 0.217 & $<0.001$ & 1.120 & $0.660,1.580$ & 0.357 \\
\hline & Anxiety severity & 0.169 & $<0.001$ & 1.047 & $0.522,1.572$ & \\
\hline & Nighttime behaviors severity & 0.145 & 0.001 & 0.730 & $0.300,1.160$ & \\
\hline & Agitation severity & 0.123 & 0.008 & 0.802 & $0.208,1.396$ & \\
\hline & Hallucinations severity & 0.101 & 0.044 & 0.711 & $0.019,1.403$ & \\
\hline \multirow[t]{5}{*}{ Physical } & Nighttime behaviors severity & 0.147 & 0.002 & 0.507 & $0.194,0.820$ & 0.275 \\
\hline & Anxiety severity & 0.133 & 0.004 & 0.564 & $0.181,0.947$ & \\
\hline & Depression severity & 0.131 & 0.006 & 0.497 & $0.141,0.853$ & \\
\hline & Apathy severity & 0.112 & 0.021 & 0.396 & $0.062,0.730$ & \\
\hline & Agitation severity & 0.096 & 0.05 & 0.432 & $0.002,0.862$ & \\
\hline \multirow[t]{3}{*}{ Emotional } & Disinhibition severity & 0.218 & $<0.001$ & 1.201 & $0.641,1.761$ & 0.210 \\
\hline & Agitation severity & 0.199 & $<0.001$ & 0.873 & $0.431,1.315$ & \\
\hline & Female sex & 0.104 & 0.019 & 0.854 & $0.141,1.567$ & \\
\hline \multirow[t]{3}{*}{ Social } & Agitation severity & 0.253 & $<0.001$ & 1.205 & $0.727,1.683$ & 0.212 \\
\hline & Age & -0.193 & $<0.001$ & -0.072 & $-0.105,-0.039$ & \\
\hline & Apathy severity & 0.103 & 0.04 & 0.389 & $0.018,0.760$ & \\
\hline
\end{tabular}

Six individual regression models were run, one for each respective CBI component, each containing all NPI severity items, age, sex, and caregiving duration. Full model shown in supplementary material

of not only the relationship between caregiver burden and neuropsychiatric symptoms but also how the source of report (patient vs caregiver) influences this. As for other limitations, our sample consisted predominantly of female spouses, predominantly white, with relatively high levels of education. It is possible that these results are not generalizable to other informal CPDs, or formal (paid) CPD. In addition, as mentioned, cognitive function and motor symptoms in the care recipient were not examined.

Our findings emphasize the strong contribution of neuropsychiatric symptoms to caregiver burden in PD. They indicate that the domains of caregiving in PD are related to demographic characteristics of the caregiver and different neuropsychiatric symptoms in the care recipient. In light of our findings, interventions aimed at improving neuropsychiatric symptoms in PD that evaluate the effect on caregivers will benefit from assessing specific domains of caregiver burden. To optimally support CPD, management strategies may need to be tailored to each domain, its contributors and the characteristics of the CPD themselves. 

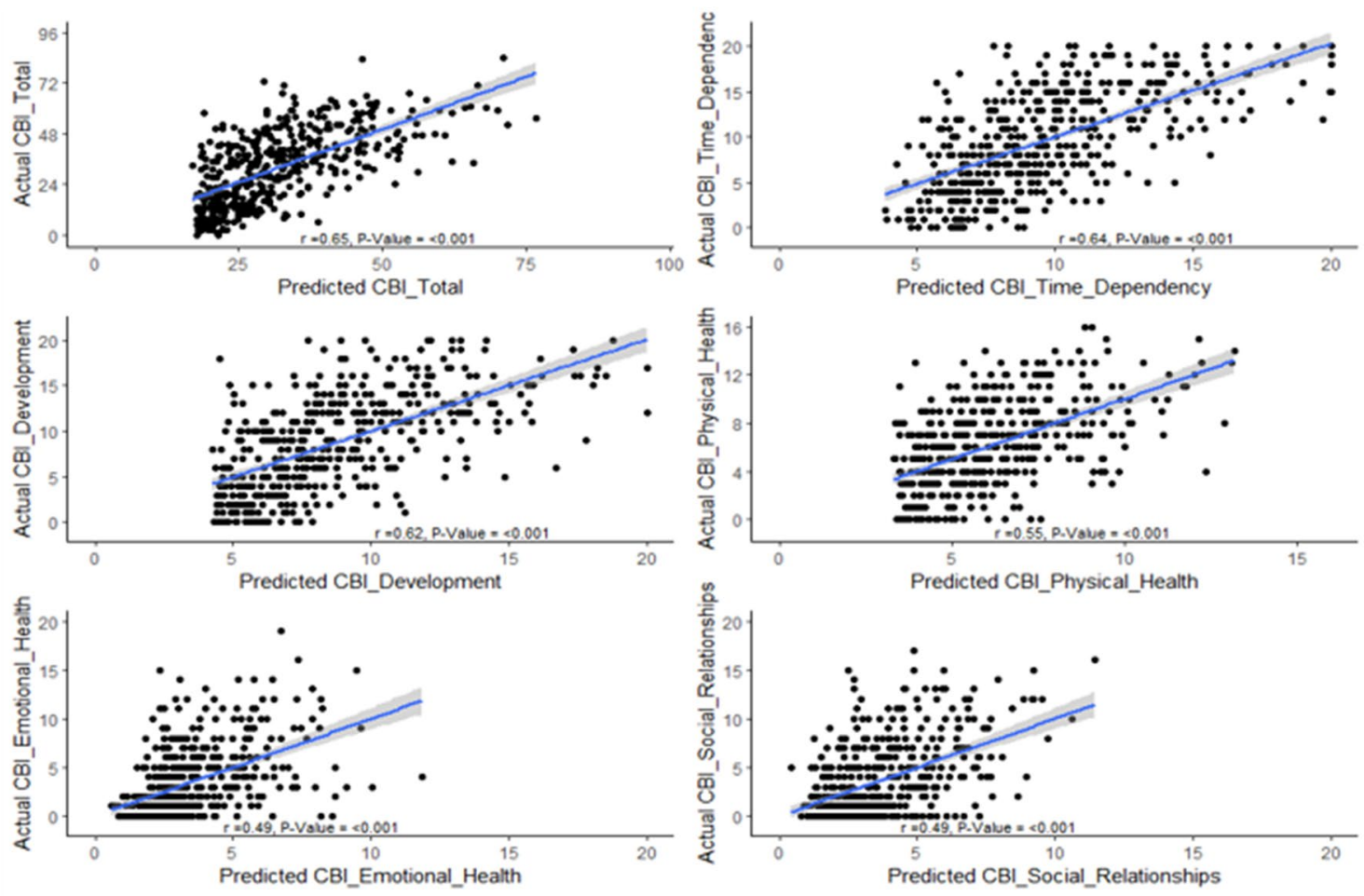

Fig. 3 Plots of expected value of CBI scores (based on the regression models from Table 3) against the actual (observed) values

Supplementary Information The online version contains supplementary material available at https://doi.org/10.1007/s00415-021-10443-7.

Acknowledgments This work was funded by The Michael J. Fox Foundation for Parkinson's Research (MJFF). This work occurred as part of the MJFF's Parkinson's Disease Education Consortium 2018 (PDEC 2018) project. The MJFF PDEC 2018 project was sponsored by the following industry partners: ACADIA Pharmaceuticals, Adamas Pharmaceuticals, Intec Pharma, Lundbeck Inc., and Sunovion Pharmaceutical which sponsored this study, is funded by ACADIA Pharmaceuticals, Adamas Pharmaceuticals, Intec Pharma, Lundbeck Inc., and Sunovion Pharmaceutical. The Fox insight (FI) study is funded by The Michael J. Fox Foundation for Parkinson's Research. We would like to thank the Parkinson's community for participating in this study to make this research possible.

Author contributions LMC: conceptualization, study design, data curation, visualization, writing-original draft manuscript preparation; RF: data analysis, visualization, and interpretation of results, review and editing of manuscript; AA: data analysis, visualization, and interpretation of results, review and editing of manuscript; BT: data analysis, visualization, and interpretation of results, review and editing of manuscript; LA: visualization of results, review and editing of manuscript; SM: conceptualization, study design, interpretation of results, review and editing of manuscript; BE: visualization of results, review and editing of manuscript; SA: results interpretation, review and editing of manuscript; MD: conceptualization, review and editing of manuscript; CK conceptualization, review and editing of manuscript; $\mathrm{CM}$ : conceptualization, study design, interpretation of results, original draft manuscript preparation.

Funding This work was funded by the Michael J Fox Foundation.
Data availability Data used in the preparation of this article are available on Fox Den at foxden.michaeljfox.org.

Code availability Code will be made available on request.

\section{Compliance with ethical standards}

Conflicts of interest The authors report no conflict of interest or competing interests related to this work.

Ethics approval This study was performed in accordance with the Declaration of Helsinki. This study and the FI study are approved by the New England Institutional Review Board, and online consent is obtained from each participant at enrollment.

Open Access This article is licensed under a Creative Commons Attribution 4.0 International License, which permits use, sharing, adaptation, distribution and reproduction in any medium or format, as long as you give appropriate credit to the original author(s) and the source, provide a link to the Creative Commons licence, and indicate if changes were made. The images or other third party material in this article are included in the article's Creative Commons licence, unless indicated otherwise in a credit line to the material. If material is not included in the article's Creative Commons licence and your intended use is not permitted by statutory regulation or exceeds the permitted use, you will need to obtain permission directly from the copyright holder. To view a copy of this licence, visit http://creativecommons.org/licenses/by/4.0/. 


\section{References}

1. Dorsey ER, Constantinescu R, Thompson JP, Biglan KM, Holloway RG, Kieburtz K, Marshall FJ, Ravina BM, Schifitto G, Siderowf A, Tanner CM (2007) Projected number of people with Parkinson disease in the most populous nations, 2005 through 2030. Neurology 68:384-386

2. GBD 2016 Neurology Collaborators (2018) Global, regional, and national burden of Parkinson's disease, 1990-2016: a systematic analysis for the global burden of disease study 2016. Lancet Neurol 17:939-953

3. Macleod AD, Counsell CE (2016) Predictors of functional dependency in Parkinson's disease. Mov Disord 31:1482-1488

4. Oguh O, Kwasny M, Carter J, Stell B, Simuni T (2013) Caregiver strain in Parkinson's disease: national Parkinson foundation quality initiative study. Parkinsonism Relat Disord 19:975-979

5. Martinez-Martin P, Arroyo S, Rojo-Abuin JM, RodriguezBlazquez C, Frades B, de Pedro CJ, Longitudinal Parkinson's Disease Patient Study (Estudio Longitudinal de Pacientes con Enfermedad de Parkinson-ELEP) Group (2008) Burden, perceived health status, and mood among caregivers of Parkinson's disease patients. Mov Disord 23:1673-1680

6. Schrag A, Hovris A, Morley D, Quinn N, Jahanshahi M (2006) Caregiver-burden in Parkinson's disease is closely associated with psychiatric symptoms, falls, and disability. Parkinsonism Relat Disord 12:35-41

7. D'Amelio M, Terruso V, Palmeri B, Di Benedetto N, Famoso G, Cottone P, Aridon P, Ragonese P, Savettieri G (2009) Predictors of caregiver burden in partners of patients with Parkinson's disease. Neurol Sci 30:171-174

8. Martinez-Martin P, Rodriguez-Blazquez C, Forjaz MJ, FradesPayo B, Aguera-Ortiz L, Weintraub D, Riesco A, Kurtis MM, Chaudhuri KR (2015) Neuropsychiatric symptoms and caregiver's burden in Parkinson's disease. Parkinsonism Relat Disord 21:629-634

9. Shin H, Lee JY, Youn J, Kim JS, Cho JW (2012) Factors contributing to spousal and offspring caregiver burden in Parkinson's disease. Eur Neurol 67:292-296

10. Aarsland D, Bronnick K, Ehrt U, De Deyn PP, Tekin S, Emre M, Cummings JL (2007) Neuropsychiatric symptoms in patients with Parkinson's disease and dementia: frequency, profile and associated care giver stress. J Neurol Neurosurg Psychiatry 78:36-42

11. Mosley PE, Moodie R, Dissanayaka N (2017) Caregiver burden in Parkinson disease: a critical review of recent literature. J Geriatr Psychiatry Neurol 30:235-252

12. Aarsland D, Marsh L, Schrag A (2009) Neuropsychiatric symptoms in Parkinson's disease. Mov Disord 24:2175-2186

13. McKinlay A, Grace RC, Dalrymple-Alford JC, Anderson TJ, Fink J, Roger D (2008) Neuropsychiatric problems in Parkinson's disease: comparisons between self and caregiver report. Aging Ment Health 12:647-653

14. Kua ZJ, Pachana NA, Byrne GJ, O’Sullivan JD, Marsh R, Torbey E, Silburn PA, Mellick GD, Dissanayaka NNW (2018) How well do caregivers detect depression and anxiety in patients with Parkinson disease? J Geriatr Psychiatry Neurol 31:227-236

15. Novak M, Guest C (1989) Application of a multidimensional caregiver burden inventory. Gerontologist 29:798-803

16. Mantri S, Klawson E, Albert S, Rapoport R, Precht C, Glancey S, Daeschler M, Mamikonyan E, Kopil C, Marras C, Chahine LM (2020) The experience of care partners of patients with Parkinson's disease psychosis. Manuscript under review

17. Mantri S, Edison B, Alzyoud L, Albert S, Daeschler M, Kopil C, Marras C, Chahine LM (2021) Knowledge, responsibilities, and peer advice from care partners of patients with Parkinson disease psychosis. Front. Neurol. 12:633645. https://doi.org/10.3389/fneur .2021 .633645

18. Smolensky L, Amondikar N, Crawford K, Neu S, Kopil C, Daeschler M, Riley L, 23andMe Research Team, Brown E, Toga AW, Tanner C (2020) Fox insight collects online, longitudinal patientreported outcomes and genetic data on Parkinson's disease. Sci Data 7:67. https://doi.org/10.1038/s41597-020-0401-2

19. Kaufer DI, Cummings JL, Ketchel P, Smith V, MacMillan A, Shelley T, Lopez OL, DeKosky ST (2000) Validation of the NPI-Q, a brief clinical form of the neuropsychiatric inventory. J Neuropsychiatry Clin Neurosci 12:233-239

20. Cummings JL, Mega M, Gray K, Rosenberg-Thompson S, Carusi DA, Gornbein J (1994) The neuropsychiatric inventory: comprehensive assessment of psychopathology in dementia. Neurology 44:2308-2314

21. Oedekovenm M, Amin-Kotb K, Gellert P, Balke K, Kuhlmey A, Schnitzer S (2019) Associations between informal caregivers' burden and educational level. J Gerontopsychology Geriatr Psychiatry 32:19-29

22. Gibson G, Mottram PG, Burn DJ, Hindle JV, Landau S, Samuel M, Hurt CS, Brown RG, Wilson KCM (2013) Frequency, prevalence, incidence and risk factors associated with visual hallucinations in a sample of patients with Parkinson's disease: a longitudinal 4-year study. Int J Geriatr Psychiatry 28:626-631

23. Broen MP, Köhler S, Moonen AJ, Kuijf ML, Dujardin K, Marsh L, Richard IH, Starkstein SE, Martinez-Martin P, Leentjens AF (2016) Modeling anxiety in Parkinson's disease. Mov Disord 31:310-316

24. Leroi I, Ahearn DJ, Andrews M, McDonald KR, Byrne EJ, Burns A (2011) Behavioural disorders, disability and quality of life in Parkinson's disease. Age Ageing 40:614-621

25. Gomez-Esteban JC, Tijero B, Somme J, Ciordia R, Berganzo K, Rouco I, Bustos JL, Valle MA, Lezcano E, Zarranz JJ (2011) Impact of psychiatric symptoms and sleep disorders on the quality of life of patients with Parkinson's disease. J Neurol 258:494-499

26. Mason A, Weatherly H, Spilsbury K, Arksey H, Golder S, Adamson J, Drummond M, Glendinning C (2007) A systematic review of the effectiveness and cost-effectiveness of different models of community-based respite care for frail older people and their carers. Health Technol Assess 11:1-157 (iii)

27. Trend P, Kaye J, Gage H, Owen C, Wade D (2002) Short-term effectiveness of intensive multidisciplinary rehabilitation for people with Parkinson's disease and their carers. Clin Rehabil 16:717-725

28. Sturkenboom IH, Graff MJ, Borm GF, Veenhuizen Y, Bloem BR, Munneke M, Nijhuis-van der Sanden MW (2013) The impact of occupational therapy in Parkinson's disease: a randomized controlled feasibility study. Clin Rehabil 27:99-112

29. Caserta MS, Lund DA, Wright SD (1996) Exploring the caregiver burden inventory (CBI): further evidence for a multidimensional view of burden. Int J Aging Hum Dev 43:21-34

30. Grün D, Pieri V, Vaillant M, Diederich NJ (2016) Contributory factors to caregiver burden in Parkinson disease. J Am Med Dir Assoc 17:626-632

31. Bartolomei L, Pastore A, Meligrana L, Sanson E, Bonetto N, Minicuci GM, Marsala SZ, Mesiano T, Bragagnolo L, Antonini A (2018) Relevance of sleep quality on caregiver burden in Parkinson's disease. Neurol Sci 39:835-839

32. Snyder CM, Fauth E, Wanzek J, Piercy KW, Norton MC, Corcoran C, Rabins PV, Lyketsos CG, Tschanz JT (2015) Dementia caregivers' coping strategies and their relationship to health and wellbeing: the cache county study. Aging Ment Health 19:390-399

33. Martin-Cook K, Remakel-Davis B, Svetlik D, Hynan LS, Weiner MF (2003) Caregiver attribution and resentment in dementia care. Am J Alzheimers Dis Other Demen 18:366-374 
34. Zahir A, Staffaroni AM, Wickham RE, Quinn CM, Sapozhnikova A, Seidman J, Chiong W (2020) Caregiver "objective attitude" toward patients with neurodegenerative disease: consequences for caregiver strain and relationship closeness. Aging Ment Health. https://doi.org/10.1080/13607863.2020.1771541

35. Pfeifer L, Horn AB, Maercker A, Forstmeier S (2017) Caregiver perception of apathy in persons with mild cognitive impairment or Alzheimer's disease: a longitudinal study. Aging Ment Health 21:494-500

36. Victor CR, Rippon I, Quinn C, Nelis SM, Martyr A, Hart N, Lamont R, Clare L (2020) The prevalence and predictors of loneliness in caregivers of people with dementia: findings from the IDEAL programme. Aging Ment Health. https://doi. org/10.1080/13607863.2020.1753014

37. Carnahan JL, Judge KS, Daggy JK, Slaven JE, Coleman N, Fortier EL, Suelzer C, Fowler NR (2020) Supporting caregivers of veterans with Alzheimer's disease and traumatic brain injury: study protocol for a randomized controlled trial. Trials 21(1):340. https ://doi.org/10.1186/s13063-020-4199-1

38. Simons G, Thompson SB, Pasqualini MCS, Members of the EduPark Consortium (2006) An innovative education programme for people with Parkinson's disease and their carers. Parkinsonism Relat Disord 12:478-485
39. Swinkels J, Tilburg TV, Verbakel E, van Groenou MB (2019) Explaining the gender gap in the caregiving burden of partner caregivers. J Gerontol B Psychol Sci Soc Sci 74:309-317

40. Carter JH, Stewart BJ, Archbold PG, Inoue I, Jaglin J, Lannon M, Rost-Ruffner E, Tennis M, McDermott MP, Amyot D, Barter R, Cornelius L, Demong C, Dobson J, Duff J, Erickson J, Gardiner N, Gauger L, Gray P, Kanigan B, Kiryluk B, Lewis P, Mistura K, Malapira T, Zoog K (1998) Living with a person who has Parkinson's disease: the spouse's perspective by stage of disease. Parkinson's study group. Mov Disord 13:20-28

41. Carter JH, Stewart BJ, Lyons KS, Archbold PG (2008) Do motor and nonmotor symptoms in PD patients predict caregiver strain and depression? Mov Disord 23:1211-1216

42. Muller AJ, Mills JMZ, O'Callaghan C, Naismith SL, Clouston PD, Lewis SJG, Shine JM (2018) Informant- and self-appraisals on the Psychosis and Hallucinations Questionnaire (PsycH-Q) enhances detection of visual hallucinations in Parkinson's disease. Mov Disord Clin Pract 5:607-613

43. Cummings J (2020) The neuropsychiatric inventory: development and applications. J Geriatr Psychiatry Neurol 33:73-84 